\title{
Academics' Perceptions of Transformation Policies for Equity in Higher Education
}

\author{
Coetzee LS ${ }^{1}$, Janse van Vuuren $\mathbf{E C}^{2}$, Adefuye, $\mathbf{A O}^{3}$ \\ ${ }^{1}$ Lecturer, Department of Optometry, Faculty of Health Sciences, University \\ of the Free State; \\ ${ }^{2}$ Adj. Prof., Head of School for Allied Health Professions, Faculty of Health Sciences \\ ${ }^{3}$ Senior Lecturer, Division Health Sciences Education, Faculty of Health Sciences, \\ University of the Free State \\ South Africa
}

\begin{abstract}
.
In order to redress the inequalities of the past, South African governmental mandates are focused towards transformation for inclusiveness, diversity and equity to previous disadvantaged populations. These policies seek to address inequality in all spheres of daily life. This study investigated the perceptions of academics to policy implementation, among 111 Faculty of Health Sciences participants. The results found a range of perceptions, relating to sustainability, succession, promotion and perceived competence of alleged political appointments. The implementation is thus, slowed down by the resistance to change, the negative perception of transformative efforts. The findings also indicate that political goals through policy promulgation are insufficient and unlikely to be successful without a change in the individuals' perceptions of these policies. Further studies are needed to identify how these perceptions can be altered and garner widespread buy-in on an individual basis for these policies, in order to shape a diverse and sustainable academic workforce into the future.
\end{abstract}

Keywords :change; decolonisation; educational reform; policy; sustainability 


\section{$2^{\text {nd }}$ International Conference on Research in \\ TEACHING and EDUCATION}

RTECONF

6-8 March, 2020

BUDAPEST,HUNGARY

South Africa is a young constitutional democracy; where up until the early 1990's social inequalities were evident. Blacks and women were systemically excluded from the workplace and other societal aspects under the apartheid legislation, which was compounded by the patriarchal colonial history of this settlement country. These inequitable and controlling legacies also affected the Higher Education (HE) system.

After the first democratic elections, the government has committed to transformation in the HE system. There have been a number of transformation-oriented initiatives executed in order to attempt to rectify the inequality of the past and effect institutional change. Through the focused implementation of regulations aimed at overcoming unfair discrimination. These initiatives are based on the constitutional principles of human dignity, equality, freedom, non-racialism and non-sexism.

Efforts to increase the number of academics, addressed in the White Paper for Post School Education and Training are made (Department of Higher Education and Training (DHET) 2014:10). This paper emphasised that there are not sufficient academics to replace the workforce that will be retiring in the next decade and university staff are encouraged to obtain higher degrees. The New Generation of Academics Programme (DHET 2015:online) involves the recruitment of highly capable scholars as new academics, taking into account the carefully designed and balanced equity considerations and in light of the disciplinary areas of highest need.

\section{Methods}

Four sub-populations from three Health Sciences schools and academic support staff comprised a population of 242 academic staff members in a Health Sciences Faculty. A sample ( $n=111)$ academic staff members completed open-ended questions via an electronically linked questionnaire. Ten nominal groups were conducted, which hosted 55 participants across the four sub-populations. The researcher and the co-coder completed four iterations of coding of the transcribed data, before the final thematic analysis took place. Both sets of data once thematically analysed, were further analysed for similarities and differences relating to the perceptions of the workplace environment, relating to research.

\section{Results}

Perceptions of the academics who participated in the study made comments relating to the implementation of policies that are mandated by government. These included perceptions on non-implementation; progress made to sustainability in academia; policies are not substantially addressing the complex issue of capacity building in higher education. Also that the transformation policies are viewed in a negative light and as being unfair. 


\section{$2^{\text {nd }}$ International Conference on Research in TEACHING and EDUCATION}

RTECONF

6-8 March, 2020

BUDAPEST,HUNGARY

There is also a perception that appointments are made based on political affiliation, resultant in sub-standard performance.

\section{Discussion}

There exist current policies aimed at creating an equitable platform for all in the arena of higher education, within the South African context. The results of this study indicated a range of perceptions relating to the implementation of transformation and promotion policies. The findings also indicate that political goals through policy promulgation are insufficient and unlikely to be successful without a change in the individuals' perceptions of these policies. In order to alter the status quo among groups of individuals, the process of change management may be implemented through strategies of transforming values and norms accepted in the organisation (Gutterman 2010:1).

At present, the intended actions of these polices are being thwarted, halting progress towards an equitable academic environment. Further studies are needed to identify how these perceptions can be altered and garner widespread buy-in on an individual basis for these policies, in order to shape a diverse and sustainable academic workforce into the future.

\section{References}

Department of Higher Education and Training (DHET). 2015. New Generation of Academics Programme.

$<$ http://www.dhet.gov.za/ssauf/ngap.html>

Department of Higher Education and Training (DHET). 2014. White Paper for Post-School Education and Training: Building an Expanded, Effective and Integrated Post-School System.

http://www.dhet.gov.za/SiteAssets/Latest\%20News/White\%20paper\%20for\%20postschool\% 20education\%20and\%20training.pdf

Gutterman, A.S. 2010. Evaluating and transforming organizational culture. http://alangutterman.typepad.com/files/omddc_evaluating_and_transforming_organizational culture.pdf 